\title{
PENGARUH E-SERVICE QUALITY TERHADAP E-SATISFACTION DAN E- LOYALTY NASABAH PENGGUNA MANDIRI ONLINE
}

\author{
Arief Budiman $^{1}$, Edy Yulianto $^{2}$, Muhammad Saifi ${ }^{3}$ \\ Fakultas Ilmu Administrasi, Universitas Brawijaya, Malang, Indonesia ${ }^{123}$ \\ Email: ariefbudimansab@gmail.com ${ }^{1}, \underline{\text { edy_y_fia@ub.ac.id }}$, $\underline{\text { Msaifi@ub.ac.id }}$
}

\begin{abstract}
This research aims to investigated the effect of e-service quality as independent variabel on e-customer satisfaction and e-customer loyalty as dependent variabel. This research is a quantitative approach with type of explanatory research. The data used are primary data obtained by distributing questionnaires directly to user mandiri online in six cities, namely Jember, Situbondo, Probolinggo, Bondowoso, Lumajang, Banyuwangi,. Purposive sampling are used as sampling method in this study.115 respondent are collected. Data analysis use Structural Equation Model (SEM). The conclusion show that online service quality have positive effect and significant on e-satisfaction and e-loyalty mandiri online user's.
\end{abstract}

Keywords: E-Service Quality, E-Satisfaction, E- Loyalty

\begin{abstract}
ABSTRAK
Penelitian ini bertujuan untuk mengetahui bagaimana pengaruh kualitas layanan online yang diberikan sistem mandiri online terhadap kepuasan serta loyalitas para penggunanya. Penelitian ini masuk dalam kategori penelitian penjelasan hubungan antar variabel atau yang biasa disebut explanatory reseearch dengan pendekatan kuantitatif. Data primer digunakan pada penelitian ini yang didapat dengan menyebarkan kuesioner secara langsung kepada pengguna mandiri online di enam kota yaitu Jember, Lumajang, Bondowoso, Situbondo, Banyuwangi, Probolinggo. Metode pengambilan sampel adalah purposive sampling sebanyak 115 responden. Metode analisis SEM dengan bantuan PLS digunakan untuk analisis data pada penelitian ini. Penelitian ini mengkonfirmasi penelitian terdahulu, bahwa kualitas layanan online terdapat pengaruh yang positif serta signifikan terhadap kepuasan dan loyalitas pengguna sistem mandiri online.
\end{abstract}

Keywords: E-Service Quality, E-Satisfaction, E- Loyalty 


\section{PENDAHULUAN}

Kualitas layanan merupakan salah satu isu penting yang dibahas perusahaan sebagai upaya menjaga eksistensi bisnisnya di tengah persaingan yang ada. Di era digital saat ini, teknologi informasi mengambil peranan yang sangat penting dalam aspek kehidupan manusia karena mempermudah dalam melakukan berbagai aktivitas, tidak terkecuali aktivitas bisnis. Perusahaan bisnis harus mampu beradaptasi, jika semula perusahaan berfokus pada kualitas produk serta bagaimana memberikan pelayanan secara langsung dengan berkualitas, kini perusahaan dihadapkan kenyataan bahwa untuk memenangkan di tengah persaingan, perusahaan harus menyediakan media online atau elektronik yang tentunya harus berkualitas juga. Mengukur kualitas pelayanan dari media elektroniknya menjadi salah satu fokus perusahaan di era digital. Parasuraman et al., (2005) mengembangkan metode untuk mengukur kualitas layanan elektronik, atau yang biasa disebut e-service quality.

E-service quality didefinisikan sebagai sebuah alat atau instrumen untuk mendapatkan ukuran tingkat kepuasan pelanggan dari sebuah layanan berbasis internet terdiri dari pembelanjaan, dan penyampaian produk atau jasa (Parasuraman et al., 2005). Pengukuran dilakukan dengan membandingkan antara ekspektasi jasa yang diharapkan dengan jasa yang diterima oleh customer tersebut. Layanan sebuah jasa atau produk yang berkualitas, tentunya akan berdampak pada kepuasan bagi penggunanya, dan rasa puas secara terus menerus yang diterima oleh pelanggan akan menciptakan sikap loyal kepada perusahaan (Griffin, 2005).

Di sektor perbankan, penelitian Charles (2016) memberikan konfirmasi bahwa hubungan e-service quality terhadap kepuasan dan loyalitas pengguna $e$-banking secara umum di Nigeria memiliki arah yang positif dan signifikan. Al Hawari (2014) yang juga melakukan penelitian di sektor perbankan namun di Negara Uni Emirate Arab, mengkonfirmasi penelitian Charles (2016) yang menyatakan bahwa kualitas layanan pada sistem $e$-banking memberikan pengaruh positif dan signifikan terhadap kepuasan yang dirasakan penggunanya, akan tetapi kualitas layanan e-banking tersebut tidak secara langsung mempengaruhi loyalitas penggunanya, sehingga hubungan e-service quality terhadap e-loyalty bersifat negatif pada penelitian ini. Berdasarkan penelitian penelitian sebelumnya dapat diambil kesimpulan, $e$ service quality secara menyeluruh memiliki hubungan dengan arah yang positif dan signifikan terhadap e-satisfaction, akan tetapi adanya gap hasil penelitian dimana pada penelitian Charles (2016) hubungan e-service quality terhadap e-loyalty memiliki arah yang positif dan signifikan, namun pada penelitian $\mathrm{Al}$ Hawari (2014) serta penelitian Othman et al. (2015) hubungan langsung e-service quality terhadap e-loyalty tidak didukung pada penelitian ini, dalam artian harus melewati variabel e-satisfaction terlebih dahulu. Sehingga penelitian yang akan dilakukan berusaha untuk mengkonfirmasi ulang bagaimana hubungan variabel $e$-service quality terhadap e-satisfaction serta e-loyalty dengan mengadopsi dimensi dari Parasuraman yaitu efficiency, system availability, privacy, responsiveness, contact serta menambahkan dimensi baru dari Ho dan Lin (2010) yang berupa web design.

Sebagai salah satu bagian dari lembaga keuangan, Sektor Perbankan harus tetap menjaga eksistensinya di era digital. Perkembangan industri perbankan menjadi semakin kompetitif, dimana layanan yang unggul merupakan kunci sukses untuk bersaing pada industri ini. Layanan menjadi sebuah diferensiasi sekaligus penentu berhasil atau tidaknya perbankan dalam menjaga nasabah yang sudah eksis maupun menjaring calon nasabah baru. Salah satu layanan yang disediakan perbankan di era digital adalah internet banking. Kemunculan internet banking sebagai salah satu inovasi yang lebih mempermudah aktivitas perbankan karena menghilangkan batas ruang dan waktu (Anggraeni dan Yasa, 2010).

Pengguna e-banking di Indonesia mengalami kenaikan dari tahun ke tahun. Data yang dihimpun dari Otoritas Jasa Keuangan (OJK) 2017, tahun 2012 terdapat 13,6 juta nasabah menggunakan e-banking, dan pada tahun 2016 pengguna e-banking menjadi 50,4 
juta nasabah. Terdapat peningkatan sebesar $270 \%$ selama kurun waktu tersebut. Jumlah pengguna e-banking di Indonesia terus mengalami peningkatan disebabkan pergeseran perilaku ke era digital masyarakat dalam pemanfaatan teknologi untuk melakukan transaksi maupun aktivitas perbankan. Frekuensi transaksi sistem e-banking juga mengalami peningkatan yaitu pada tahun 2012 terdapat 150,8 juta transaksi, dan di tahun 2016 terdapat 405,4 juta transaksi. Terdapat peningkatan sebesar $169 \%$ infobanknews, (2018). Data tersebut mengindikasikan bahwa potensi dan peluang perbankan dalam penyediaan produk $e$-banking nya masih sangat terbuka lebar.

Menjadi sebuah tuntutan bagi sektor perbankan dalam melakukan evaluasi layanan internet banking secara berkualitas, dikarenakan semakin berkualitas sebuah layanan internet banking, maka perasaan senang terhadap penggunaan internet banking tersebut akan semakin meningkat, yang pada akhirnya memberikan dampak sikap loyal terhadap penggunaan layanan tersebut.

Bank Mandiri merupakan salah satu bank terbesar di Indonesia yang tentunya dihadapkan pada tantangan perkembangan teknologi informasi. Dengan visinya di tahun 2018 yaitu Indonesia's Best Asean's Prominent, Bank Mandiri berusaha untuk menjadi bank terbaik di Indonesia. Menurut Joseph Georgio, Chief Technology Officer Bank Mandiri, inovasi di bidang layanan elektronik menjadi sebuah keharusan, hal ini dikarenakan salah satu tantangan yang dihadapi adalah perilaku nasabah saat ini yang lebih menyukai untuk bertransaksi secara online daripada datang langsung ke kantor cabang. (kontan, 2018).

Sebagai upaya untuk menang ditengah persaingan, Bank Mandiri terus melakukan inovasi, dan inovasi yang terbaru dibidang teknologi yang diluncurkan Bank Mandiri di awal tahun 2017 adalah mandiri online. Mandiri online merupakan integrasi dari sistem sebelumnya yaitu mandiri internet banking dan mandiri mobile banking. Mandiri online memberikan experience yang jauh lebih baik untuk penggunanya dalam melakukan transaksi keuangan secara online. Jika yang terdahulu mandiri internet banking dan mandiri mobile banking merupakan dua akun yang berbeda, kini ketika nasabah sudah memiliki akun mandiri online, maka dia dapat mengaksesnya di dua platform yang berbeda yaitu akses melalui website dan juga akses menggunakan aplikasi. Fitur yang diberikan pun semakin lengkap, tidak hanya fasilitas transaksi finansial secara online, dengan mengakses mandiri online, pengguna juga dapat memperoleh informasi terkait seluruh portofolio keuangan mereka secara detail. Kemudahan lainnya yaitu pengguna dapat melakukan pembukaan rekening deposito dan tabungan rencana mandiri secara online.

Dari banyaknya keunggulan tersebut, mandiri online yang tergolong produk baru, tidak lepas dari kekurangan yang menyertainya. Dipertengahan tahun 2017 sempat terdengar berita mengenai mandiri online, dimana dana dari beberapa nasabah tiba-tiba hilang, sehingga muncul komplain dari nasabah. Kasus tersebut memberikan pelajaran bahwa diperlukan sebuah evaluasi untuk menilai kualitas layanan dari sebuah sistem, agar komplain dan ketidakpuasan tidak terjadi kembali dikemudian hari.

Penelitian yang akan dilakukan mengangkat objek mandiri online dikarenakan sistem tersebut merupakan produk terbaru dari Bank Mandiri yang mengintegrasikan antara mandiri internet dengan mandiri mobile dimana dalam perjalanannya masih terdapat beberapa trouble seperti yang telah dipaparkan diatas. Adapun lokasi penelitian yang akan dilakukan adalah di Bank Mandiri Area Jember yang lokasinya terdiri dari beberapa kota yaitu Jember, Banyuwangi, Probolinggo, Lumajang, Situbondo, Bondowoso.

Bank Mandiri Area Jember merupakan area dengan cakupan wilayah terbesar, dimana pada tahun 2018 Bank Mandiri Area Jember memperoleh penghargaan sebagai area dengan kinerja terbaik di Jawa Timur. Akan tetapi, berdasarkan pengamatan yang dilakukan, masih banyak terdapat komplain dari nasabah terkait mandiri online diantaranya susah login, proses transaksi yang lama. Sehingga tujuan dalam penelitian ini adalah untuk menjelaskan pengaruh kualitas layanan dalam konteks online (e-service quality) sistem mandiri online terhadap kepuasan dan loyalitas para penggunanya. 


\section{KAJIAN PUSTAKA}

Tinjauan empirik pada penelitian terdiri dari beberapa penelitian terdahulu diantaranya Al Hawari (2014) yang melakukan investigasi pengaruh antara kualitas layanan online di industri perbankan Uni Emirate Arab terhadap tingkat kepuasan dan loyalitas nasabanya di berbagai tingkat sosial. Hasil penelitian menyatakan bahwa e-quality merupakan variabel yang memengaruhi e-satisfaction, yang pada gilirannya memengaruhi e-loyalty. Dalam penelitian ini juga dikonfirmasi bahwa jika pengguna $e$-banking tersebut seorang introvert (kurang sosial) maka pengaruh kualitas layanan ebanking terhadap kepuasan dan loyalitas pengguna tersebut lebih kuat jika dibandingkan apabila pengguna e-banking merupakan seorang yang extravert (sangat sosial). Hubungan variabel $e$-service quality dengan $e$ loyalty secara langsung tidak didukung penelitian ini.

Othman et al. (2015) meneliti terkait hubungan kualitas layanan online, kepuasan, serta kepercayaan dalam konteks online terhadap loyalitas pengguna perbankan online di Malaysia. Hasil penelitian menunjukkan bahwa loyalitas nasabah perbankan online di Malaysia tidak secara otomatis ditentukan oleh kualitas layanan dari sistem e-banking yang diberikan, dalam artian kualitas layanan yang baik tidak menjamin seorang pengguna $e$ banking menjadi loyal. E-loyality atau loyalitas online hanya bisa dipastikan saat ada $e$ satisfaction dan e-trust.

Charles et al. (2016) melakukan penelitian terkait tingkat kepuasan dan loyalitas pengguna terhadap kualitas layanan sistem e-banking di Nigeria. Hasil penelitian menunjukkan di Negara Nigeria, kualitas layanan dari sistem $e$ banking nya berpengaruh positif terhadap kepuasan dan loyalitas penggunanya.

Menurut Parasuraman et al. (2005) eservice quality didefinisikan sebagai tingkat efisiensi dan efektifitas sebuah website memfasilitasi dalam hal berbelanja, pembelian serta proses penyerahan produk dan jasa. Penilaian kualitas layanan tersebut dilakukan selama interaksi dengan website, dan juga setelah mendapatkan layanan. Parasuraman et al. (2005) membagi kualitas layanan online menjadi 2 jenis yaitu eCore Service Quality (E$S$-Qual) dengan dimensinya efficiency, system availabilty, fullfillment, dan privacy dan tiga dimensi e-recovery service quality (E-RecS$Q U A L)$ yaitu responsiveness, compensation, dan contact. Empat dimensi pertama dari E-SQual terkait dengan layanan online inti, sedangkan E-RecS-QUAL menangani masalah yang dihadapi selama ini setelah proses pembelian online

Anderson dan Srinivasan menyatakan bahwa kepuasan online atau yang biasa disebut dengan e-satisfaction adalah sebuah penilaian oleh customer dalam setiap bertransaksi secara online. E-satisfaction dianggap sebagai pemenuhan kebutuhan customer terhadap perasaan senang yang dikumpulkan selama beberapa pengalaman transaksi dengan media online sehingga mengakibatkan evaluasi secara keseluruhan.

Loyalitas dikaitkan dengan layanan online dimana mengacu pada pendapat Griffin (2005) yang menyatakan bahwa loyalitas online atau yang biasa disebut dengan e-customer loyalty merupakan sikap secara sukarela dari pelanggan terhadap suatu bisnis elektronik yang mengakibatkan penggunaan berulang. Anderson dan Srinivasan (2003:13) mengemukakan 5 dimensi e-loyalty, yaitu : Positive word of mouth, rekomendasi kepada yang lain, mendorong yang lain untuk menggunakan, menjadikan pilihan pertama di masa mendatang.

\section{METODE PENELITIAN}

Studi yang dilakukan ini tergolong ke dalam jenis penelitian eksplanatory research dikarenakan pada studi ini bertujuan untuk menjelaskan pengaruh atau hubungan antar variabel dengan cara menguji hipotesis yang telah dirumuskan (Singarimbun dan Effendi, 2009). Sumber data pada penelitian ini yaitu data primer. Teknik pengumpulan data yaitu metode survey dengan instrumen penelitian yang berupa kuesioner. Kuesioner penelitian diberikan secara langsung kepada pengguna mandiri online yang berjumlah 115 responden, dengan cara standby di kantor Bank Mandiri yang tersebar di enam kota yaitu Jember, Lumajang, Banyuwangi, Probolinggo, Bondowoso, Situbondo. Kuesioner tersebut berisi sejumlah pernyataan, dimana responden diminta untuk 
memberikan tanggapan atas pernyataanpernyataan yang sesuai dengan persepsi mereka selama menggunakan sistem mandiri online.

Tabel 1. Karakteristik Responden

\begin{tabular}{|c|c|c|}
\hline $\begin{array}{l}\text { Karakteristik } \\
\text { Demografis } \\
\end{array}$ & $\begin{array}{l}\text { Frekuensi } \\
\text { (f) }\end{array}$ & $\begin{array}{c}\text { Persentasi } \\
(\%) \\
\end{array}$ \\
\hline \multicolumn{3}{|l|}{ Jenis Kelamin } \\
\hline Laki-laki & 52 & 45,20 \\
\hline Perempuan & 63 & 54,80 \\
\hline \multicolumn{3}{|l|}{ Umur } \\
\hline 19-23 Tahun & 6 & 5.21 \\
\hline 24-28 Tahun & 27 & 23.47 \\
\hline 29-33 Tahun & 21 & 18.26 \\
\hline 34-38 Tahun & 13 & 11.30 \\
\hline 39-43 Tahun & 16 & 13.91 \\
\hline 44-48 Tahun & 7 & 6.08 \\
\hline 49-53 Tahun & 11 & 9.56 \\
\hline 54-58 Tahun & 9 & 7.82 \\
\hline 59-63 Tahun & 5 & 4.34 \\
\hline \multicolumn{3}{|l|}{ Pendidikan } \\
\hline $\mathrm{SD}$ & 7 & 6.08 \\
\hline SMP & 10 & 8.69 \\
\hline SMU/SMK & 38 & 33.04 \\
\hline Diploma & 11 & 9.56 \\
\hline $\mathrm{S} 1$ & 41 & 35.65 \\
\hline $\mathrm{S} 2$ & 6 & 5.21 \\
\hline S3 & 2 & 1.73 \\
\hline \multicolumn{3}{|l|}{ Pekerjaan } \\
\hline PNS & 13 & 11.30 \\
\hline Pegawai Swasta & 30 & 26.08 \\
\hline Wiraswasta & 48 & 41.73 \\
\hline TNI/Polri & 7 & 6.08 \\
\hline Lainnya & 17 & 14.78 \\
\hline \multicolumn{3}{|l|}{ Domisili } \\
\hline Jember & 30 & 26.08 \\
\hline Lumajang & 18 & 15.65 \\
\hline Bondowoso & 9 & 7.82 \\
\hline Probolinggo & 21 & 18.26 \\
\hline Banyuwangi & 26 & 22.60 \\
\hline Situbondo & 11 & 9.56 \\
\hline
\end{tabular}

Sumber: Data Primer(2018)

Teknik pengolahan data yaitu menggunakan metode Structural Equation Model (SEM) berbasis Partial Least Square (PLS) dengan Software PLS versi 2.0 M3.

Tabel 2. Outer Loadings (Mean, STDEV, TValues)

\begin{tabular}{|c|c|c|c|}
\hline & $\begin{array}{l}\text { Original } \\
\text { Sample(O } \\
\text { ) }\end{array}$ & $\begin{array}{l}\text { Standard } \\
\text { Deviation } \\
\text { (STDEV) }\end{array}$ & $\begin{array}{l}\text { T Statistic } \\
\text { (|O/STERR })\end{array}$ \\
\hline X1.1<- X1 & 0,736 & 0.049 & 14.927 \\
\hline X1.2<- X1 & 0.841 & 0.033 & 25.412 \\
\hline X1.3<- X1 & 0.755 & 0.056 & 13.599 \\
\hline X1.4<- X1 & 0.862 & 0.039 & 22.167 \\
\hline X1.5<- X1 & 0.716 & 0.063 & 11.393 \\
\hline X2.1<- X2 & 0.733 & 0.046 & 15.822 \\
\hline X2.2<- X2 & 0.829 & 0.041 & 19.999 \\
\hline X2.3<- X2 & 0.772 & 0.069 & 11.194 \\
\hline
\end{tabular}

\begin{tabular}{|l|l|l|l|}
\hline $\mathrm{X} 2.4<-\mathrm{X} 2$ & 0.773 & 0.071 & 10.940 \\
\hline $\mathrm{X} 3.1<-\mathrm{X} 3$ & 0.882 & 0.026 & 34.283 \\
\hline $\mathrm{X} 3.2<-\mathrm{X} 3$ & 0.921 & 0.013 & 72.144 \\
\hline $\mathrm{X} 3.3<-\mathrm{X} 3$ & 0.912 & 0.023 & 40.496 \\
\hline $\mathrm{X} 4.1<-\mathrm{X} 4$ & 0.838 & 0.030 & 27.861 \\
\hline $\mathrm{X} 4.2<-\mathrm{X} 4$ & 0.860 & 0.031 & 27.613 \\
\hline $\mathrm{X} 4.3<-\mathrm{X} 4$ & 0.862 & 0.030 & 28.521 \\
\hline $\mathrm{X} 4.4<-\mathrm{X} 4$ & 0.874 & 0.021 & 41.342 \\
\hline $\mathrm{X} 5.1<-\mathrm{X} 5$ & 0.778 & 0.043 & 18.128 \\
\hline $\mathrm{X} 5.2<-\mathrm{X} 5$ & 0.860 & 0.028 & 30.631 \\
\hline $\mathrm{X} 5.3<-\mathrm{X} 5$ & 0.891 & 0.021 & 43.306 \\
\hline $\mathrm{X} 6.1<-\mathrm{X} 6$ & 0.782 & 0.054 & 14.471 \\
\hline $\mathrm{X} 6.2<-\mathrm{X} 6$ & 0.702 & 0.072 & 9.690 \\
\hline $\mathrm{X} 6.3<-\mathrm{X} 6$ & 0.857 & 0.026 & 33.349 \\
\hline $\mathrm{Y} 1.1<-\mathrm{Y} 1$ & 0.820 & 0.038 & 21.557 \\
\hline $\mathrm{Y} 1.2<-\mathrm{Y} 1$ & 0.809 & 0.039 & 21.019 \\
\hline $\mathrm{Y} 1.3<-\mathrm{Y} 1$ & 0.849 & 0.037 & 22.978 \\
\hline $\mathrm{Y} 2.1<-\mathrm{Y} 2$ & 0.803 & 0.038 & 21.229 \\
\hline $\mathrm{Y} 2.2<-\mathrm{Y} 2$ & 0.821 & 0.046 & 17.907 \\
\hline $\mathrm{Y} 2.3<-\mathrm{Y} 2$ & 0.840 & 0.040 & 20.903 \\
\hline $\mathrm{Y} 2.4<-\mathrm{Y} 2$ & 0.883 & 0.020 & 45.160 \\
\hline $\mathrm{Y} 2.5<-\mathrm{Y} 2$ & 0.785 & 0.046 & 17.079 \\
\hline $\mathrm{Sumber}$ & \\
\hline
\end{tabular}

Sumber: Hasil Analisis PLS, 2019

Tabel 2 merupakan tabel yang menggambarkan nilai faktor loading (convergent validity) dari setiap indikator. Validitas konvergen bertujuan untuk mengetahui apakah item pertanyaan yang digunakan valid untuk mengukur variabel latennya. Menggunakan bantuan Partial Least Square (PLS) yang dinilai berdasarkan korelasi antara skor item atau component score dengan skor variabel laten atau construct score. Nilai faktor loading > 0,7 dapat dikatakan valid, akan tetapi rule of thumbs intrepretasi nilai faktor loading > 0,5 dapat dikatakan valid. Dari tabel ini, diketahui bahwa semua nilai faktor loading dari indikator seluruh variabel lebih besar dari 0,7 . Hasil ini menunjukan bahwa indikator indikator yang diukur tersebut valid.

Tabel 3. Nilai Discriminant Validity (Cross Loading)

\begin{tabular}{|c|c|c|c|c|}
\hline & $\mathrm{X} 1$ & $\mathrm{X} 2$ & $\mathrm{X} 3$ & $\mathrm{X} 4$ \\
\hline $\mathrm{X} 1.1$ & $\mathbf{0 . 7 3 6}$ & 0.215 & 0.316 & 0.447 \\
\hline $\mathrm{X} 1.2$ & $\mathbf{0 . 8 4 1}$ & 0.314 & 0.349 & 0.463 \\
\hline $\mathrm{X} 1.3$ & $\mathbf{0 . 7 5 5}$ & 0.494 & 0.292 & 0.430 \\
\hline $\mathrm{X} 1.4$ & $\mathbf{0 . 8 6 2}$ & 0.385 & 0.301 & 0.475 \\
\hline
\end{tabular}




\begin{tabular}{|c|c|c|c|c|}
\hline $\mathrm{X} 1.5$ & 0.716 & 0.703 & 0.249 & 0.416 \\
\hline X2.1 & 0.425 & 0.733 & 0.268 & 0.422 \\
\hline $\mathrm{X} 2.2$ & 0.571 & 0.829 & 0.206 & 0.375 \\
\hline X2.3 & 0.301 & 0.772 & 0.105 & 0.184 \\
\hline $\mathrm{X} 2.4$ & 0.411 & 0.773 & 0.238 & 0.208 \\
\hline X3.1 & 0.342 & 0.176 & 0.882 & 0.408 \\
\hline X3.2 & 0.335 & 0.333 & 0.921 & 0.473 \\
\hline X3.3 & 0.369 & 0.213 & 0.912 & 0.480 \\
\hline $\mathrm{X} 4.1$ & 0.518 & 0.353 & 0.345 & $\mathbf{0 . 8 3 8}$ \\
\hline $\mathrm{X} 4.2$ & 0.441 & 0.249 & 0.451 & 0.860 \\
\hline $\mathrm{X} 4.3$ & 0.434 & 0.346 & 0.394 & 0.862 \\
\hline $\mathrm{X} 4.4$ & 0.556 & 0.401 & 0.526 & 0.874 \\
\hline X5.1 & 0.343 & 0.174 & 0.348 & 0.476 \\
\hline $\begin{array}{r}\mathrm{X} 5.2 \\
\end{array}$ & 0.259 & 0.285 & 0.222 & 0.436 \\
\hline $\begin{array}{r}\mathrm{X} 5.3 \\
\end{array}$ & 0.357 & 0.415 & 0.285 & 0.529 \\
\hline X6.1 & 0.399 & 0.205 & 0.407 & 0.425 \\
\hline X6.2 & 0.307 & 0.377 & 0.279 & 0.247 \\
\hline X6.3 & 0.569 & 0.274 & 0.573 & 0.490 \\
\hline Y1.1 & 0.447 & 0.415 & 0.348 & 0.431 \\
\hline Y1.2 & 0.519 & 0.200 & 0.528 & 0.617 \\
\hline Y1.3 & 0.456 & 0.263 & 0.390 & 0.463 \\
\hline Y2.1 & 0.536 & 0.318 & 0.476 & 0.617 \\
\hline $\mathrm{Y} 2.2$ & 0.594 & 0.412 & 0.234 & 0.514 \\
\hline Y2.3 & 0.552 & 0.331 & 0.313 & 0.505 \\
\hline $\mathrm{Y} 2.4$ & 0.625 & 0.489 & 0.426 & 0.586 \\
\hline \multirow[t]{2}{*}{$\mathrm{Y} 2.5$} & 0.462 & 0.468 & 0.452 & 0.499 \\
\hline & $\mathrm{X} 5$ & X6 & $\mathrm{Y} 1$ & $\mathrm{Y} 2$ \\
\hline $\mathrm{X} 1.1$ & 0.366 & 0.397 & 0.420 & 0.427 \\
\hline $\mathrm{X} 1.2$ & 0.290 & 0.548 & 0.510 & 0.624 \\
\hline $\mathrm{X} 1.3$ & 0.229 & 0.416 & 0.418 & 0.519 \\
\hline $\mathrm{X} 1.4$ & 0.328 & 0.457 & 0.477 & 0.515 \\
\hline $\mathrm{X} 1.5$ & 0.284 & 0.359 & 0.419 & 0.532 \\
\hline $\mathrm{X} 2.1$ & 0.403 & 0.278 & 0.262 & 0.391 \\
\hline $\mathrm{X} 2.2$ & 0.257 & 0.281 & 0.399 & 0.536 \\
\hline $\mathrm{X} 2.3$ & 0.207 & 0.217 & 0.208 & 0.228 \\
\hline $\mathrm{X} 2.4$ & 0.204 & 0.310 & 0.209 & 0.322 \\
\hline $\mathrm{X} 3.1$ & 0.287 & 0.424 & 0.374 & 0.370 \\
\hline $\mathrm{X} 3.2$ & 0.309 & 0.561 & 0.548 & 0.474 \\
\hline $\mathrm{X} 3.3$ & 0.321 & 0.507 & 0.453 & 0.410 \\
\hline $\mathrm{X} 4.1$ & 0.487 & 0.342 & 0.517 & 0.542 \\
\hline $\mathrm{X} 4.2$ & 0.464 & 0.398 & 0.430 & 0.512 \\
\hline $\mathrm{X} 4.3$ & 0.530 & 0.447 & 0.522 & 0.531 \\
\hline $\mathrm{X} 4.4$ & 0.483 & 0.546 & 0.611 & 0.671 \\
\hline X5.1 & $\mathbf{0 . 7 7 8}$ & 0.445 & 0.323 & 0.320 \\
\hline X5.2 & 0.860 & 0.383 & 0.281 & 0.217 \\
\hline X5.3 & 0.891 & 0.400 & 0.370 & 0.306 \\
\hline X6.1 & 0.532 & $\mathbf{0 . 7 8 2}$ & 0.500 & 0.409 \\
\hline X6.2 & 0.239 & 0.702 & 0.573 & 0.556 \\
\hline X6.3 & 0.351 & 0.857 & 0.595 & 0.570 \\
\hline
\end{tabular}

\begin{tabular}{|c|l|l|l|l|} 
Y1.1 & 0.166 & 0.594 & $\mathbf{0 . 8 2 0}$ & 0.699 \\
\hline Y1.2 & 0.363 & 0.474 & $\mathbf{0 . 8 0 9}$ & 0.614 \\
\hline Y1.3 & 0.435 & 0.679 & $\mathbf{0 . 8 4 9}$ & 0.619 \\
\hline Y2.1 & 0.319 & 0.544 & 0.673 & $\mathbf{0 . 8 0 3}$ \\
\hline Y2.2 & 0.114 & 0.463 & 0.637 & $\mathbf{0 . 8 2 1}$ \\
\hline Y2.3 & 0.234 & 0.525 & 0.587 & $\mathbf{0 . 8 4 0}$ \\
\hline Y2.4 & 0.384 & 0.609 & 0.687 & $\mathbf{0 . 8 8 3}$ \\
\hline Y2.5 & 0.312 & 0.527 & 0.634 & $\mathbf{0 . 7 8 5}$ \\
\hline
\end{tabular}

Sumber: Hasil Analisis PLS, 2019

Tabel 3 menunjukkan bahwa semua variaabel telah memenuhi discriminant validity karena dapat dilihat masing-masing item, telah pada variabelnya masing masing (nilai yang dicetak tebal), nilai outer loading terbesar untuk variabel yang dibentuknya dan tidak pada variabel yang lain. Oleh karenanya semua variabel telah memenuhi discriminant valid.

Tabel 4. Nilai R-Square

\begin{tabular}{|l|l|}
\hline Variabel & R-Square \\
\hline Y1 & 0.4971 \\
\hline Y2 & 0.6878 \\
\hline
\end{tabular}

Sumber: Analisis PLS, 2019

Tabel 4 memberikan arti bahwa nilai $R$ square untuk variabel E-Satisfaction (Y1) diperoleh sebesar 0,4971. Angka tersebut menunjukkan bahwa besarnya pengaruh variabel e-service quality terhadap $e$ satisfaction yaitu sebesar $49.71 \%$, dan sebesar $50,29 \%$ sisanya, dipengaruhi oleh konstruk lain di luar penelitian ini. Nilai R-square Y2 sebesar 0,6878 menunjukkan bahwa sebesar $68,78 \%$ variabel e-loyalty (Y2) dipengaruhi oleh variabel e--service quality $(\mathrm{X})$, dan $e$ satiisfaction (Y1), sebesar $31,22 \%$ sisanya, dipengaruhi oleh konstruk lain di luar yang diteliti.

Tabel 5. Path Coefficiient (Mean, STDEV, TValues)

\begin{tabular}{|c|c|c|c|}
\hline $\begin{array}{c}\text { Hubungan } \\
\text { Variabel }\end{array}$ & $\begin{array}{c}\text { Original } \\
\text { Sample } \\
(O)\end{array}$ & $\begin{array}{c}\text { Standard } \\
\text { Deviation } \\
(\text { STDEV })\end{array}$ & $\begin{array}{c}T \\
\text { Statisti } \\
c s \\
(\mid O / S T \\
\text { ERR } \mid)\end{array}$ \\
\hline $\mathrm{X}->\mathrm{Y} 1$ & 0.705 & 0.051 & 13.810 \\
\hline $\mathrm{X}->\mathrm{Y} 2$ & 0.396 & 0.090 & 4.390 \\
\hline $\mathrm{Y} 1$-> Y2 & 0.501 & 0.092 & 5.465 \\
\hline
\end{tabular}

Sumber : Hasil Analisis PLS, 2019

Berdasarkan pada Tabel 5. di dapatkan hasil sebagai berikut : 
Persamaam struktural yang didapat adalah :

$\mathrm{Y} 1=0,705 \mathrm{X}$

$\mathrm{Y}=0,396 \mathrm{X}+0,501 \mathrm{Y} 1$

\section{Pengaruh Tidak Langsung}

Terdapat dugaan variabel e-satisfaction bertindak sebagai intervening variable pada hubungan e-service quality mandiri online terhadap e-loyalty pada penelitian ini. Besarnya nilai intervening variable didapat pada perhitungan sebagai berikut:

Persamaan struktural:

$\mathrm{Y}=\mathrm{PYX}+(\mathrm{PYX} \times \mathrm{PYZ})$

Pengaruh langsung (direct effect) e-service quality terhadap e-loyalty sebesar 0,396

Indirect Effect $(\mathrm{IE}) \quad=\mathrm{PY} 1 \mathrm{X} \times \mathrm{PY} 1 \mathrm{Y} 2$

$$
\begin{aligned}
& =0,705 \times 0,501 \\
& =0,353
\end{aligned}
$$

Total Effect (TE)

$$
\begin{aligned}
& \text { PY1Y2) } \\
& =0,396+0,353 \\
& =0,749
\end{aligned}
$$$$
=\mathrm{PY} 2 \mathrm{X}+(\mathrm{PXY} 1 \times
$$

Pengaruh tidak langsung dan total pengaruh

\begin{tabular}{|c|c|c|c|c|c|c|c|}
\hline \multirow[b]{2}{*}{$\begin{array}{c}\text { Variab } \\
\text { el }\end{array}$} & \multicolumn{2}{|c|}{$\begin{array}{l}\text { Koefisien } \\
\text { Langsung }\end{array}$} & \multicolumn{2}{|c|}{$\begin{array}{l}\text { standar } \\
\text { error }\end{array}$} & \multirow[b]{2}{*}{$\begin{array}{c}\text { Koefis } \\
\text { ien } \\
\text { Tidak } \\
\text { Langs } \\
\text { ung }\end{array}$} & \multirow[b]{2}{*}{$\begin{array}{l}\text { se } \\
\text { So } \\
\text { bel }\end{array}$} & \multirow[b]{2}{*}{$\begin{array}{c}\mathrm{t} \\
\mathrm{Hitu} \\
\mathrm{ng}\end{array}$} \\
\hline & $\begin{array}{l}\mathrm{X} \\
\rightarrow \\
\mathrm{Y}_{1}\end{array}$ & $\begin{array}{l}\mathrm{Y}_{1} \\
\overrightarrow{\mathrm{Y}_{2}}\end{array}$ & $\begin{array}{l}\mathrm{X} \\
\overrightarrow{\mathrm{Y}} \\
\mathrm{Y} \\
1\end{array}$ & $\begin{array}{l}\mathrm{Y} \\
1 \\
\overrightarrow{\mathrm{Y}}\end{array}$ & & & \\
\hline $\begin{array}{l}X \rightarrow Y \\
1 \rightarrow Y 2\end{array}$ & $\begin{array}{l}0.7 \\
050\end{array}$ & $\begin{array}{l}0.5 \\
014\end{array}$ & $\begin{array}{l}0 . \\
05 \\
11\end{array}$ & $\begin{array}{l}0 . \\
09 \\
17\end{array}$ & 0.353 & $\begin{array}{l}0.0 \\
697\end{array}$ & 5.072 \\
\hline
\end{tabular}
hubungan antar variabel dengan menggunakan rumus Sobel telah disajikan dalam sebuah ringkasan hasil pada tabel berikut

Tabel 6. Rekapitulasi Pengaruh Tidak Langsung

Sumber: Hasil Analisis PLS, 2019

\section{Gambar Hasil Uji Hipotesis}

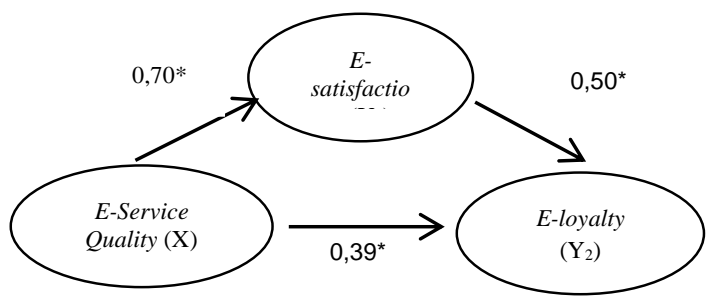

Keterangan: *signifikan

\section{PEMBAHASAN}

\section{Pengaruh E-Service Quality terhadap $E$ - Satisfaction.}

Nilai koefisien jalur dari uji variabel $X$ terhadap Y1 diperoleh nilai sebesar 0,705. Nilai t-hitung sebesar 13,810 (dibandingkan dengan nilai $\mathrm{t}$-tabel 1,96 ) dan hasilnya lebih besar $\mathrm{t}$ hitung, atau $\mathrm{p}<0,05$. Hasil tersebut menunjukkan bahwa variabel dependen (Y1) $E$ satisfaction dipengaruhi secara positif dan signifikan oleh E-Service Quality yang bertindak sebagai variabel independen, sehingga Hipotesis 1 diterima.

Penelitian ini mengkonfirmasi penelitian sebelumnya, yaitu Sheng dan Liu (2010) yang meneliti tingkat kepuasan dan loyalitas pengguna e-commerce di China, dengan variabel indpependen $e$-service quality. Secara keseluruhan kepuasan dan loyalitas pengguna $e$ commerce di China dipengaruhi oleh e-service quality dengan arah yang positif dan signifikan. Hasil Peneltian Kim (2010) juga menyebutkan bahwa kepuasan pengguna internet di Amerika dan Korea Selatan, dipengaruhi oleh variabel $e$ service quality yang terdiri dari dimensi privacy, efficiency, system availability dan fulfillment, arahnya pun sama yaitu positif dan signifikan. Hasil Penelitian Al Hawari (2014) juga menyatakan bahwa kepuasan pengguna $e$ banking di Uni Emirate Arab juga dipengaruhi oleh variabel $e$-service quality. Charles (2016) yang melakukan penelitian terhadap rasa puas nasabah e-banking di Nigeria juga mengkonfirmasi dan setuju bahwa kepuasan nasabah $e$-banking di Nigeria dipengaruhi oleh e-service quality secara positif dan signifikan. Sehingga sebagai upaya untuk meningkatkan kepuasan terhadap sistem mandiri online, Bank Mandiri perlu memberikan perhatian terhadap 
kualitas layanan dari sistem mandiri online tersebut.

Pada variabel e-service quality dalam penelitian ini, diperoleh nilai rata-rata dari masing-masing indikator sebesar 4,06 dari 5 poin total skala Likert. Sehingga dapat disimpulkan rata rata responden berpendapat setuju pada penelitian ini, bahwa e-service quality yang diberikan oleh sistem mandiri online selama ini telah baik. Kualitas layanan online yang baik ditunjukkan oleh kemudahan serta kecepatan dalam mengakses sistem mandiri online, fungsi teknik yang benar, keamanan serta perlindungan informasi terhadap pengguna, penanganan terhadap sebuah masalah sistem, ketersediaan call center yang online, serta terkait desain sebuah website yang menarik dan memberikan kemudahan bagi penggunanya.

Dari variabel $e$-satisfaction diperoleh bahwa nilai rata-rata dari masing-masing indikator dalam e- satisfaction sebesar 4,14 dari total skala likert dengan menggunakan 5 poin skala. Nilai tersebut menunjukkan bahwa dalam penelitian ini responden merasa puas dengan $e$ service quality yang diberikan oleh sistem mandiri online. Rasa puas tersebut ditunjukkan dengan pernyataan responden berupa perasaan senang terhadap keseluruhan pengalaman bertransaksi menggunakan mandiri online, senang terhadap sistem keamanannya, serta senang terhadap tampilan sistem mandiri online.

\section{Hubungan Variabel E-Service Quality terhadap E-Loyalty.}

Hasil pengujian hipotesis hubungan $e$ service quality terhadap e-loyalty menunjukkan nilai koefisien jalur sebesar 0,396, nilai tersebut menunjukkan angka yang positif. Nilai t-hitung diperoleh sebesar 4,390 (dibandingkan dengan nilai $t$ tabel 1,96) dan hasilnya lebih besar $t-$ hitung, perbandingan tersebut menunjukkan signifikansi. Sehingga dapat disimpulkan bahwa e-service quality pada sistem mandiri online berpengaruh secara positif dan signifikan terhadap e-loyalty penggunanya. Hipotesis 2 diterima.

Diperoleh nilai rata-rata (mean) indikator bernilai 4,06 dari 5 poin pada skala likert berdasarkan uji deskriptif pada variabel $e$ service quality, sehingga disimpulkan variabel kualitas layanan pada sistem mandiri online telah berjalan dengan baik. Pada variabel $e$ loyalty didapatkan nilai rata - rata indikator sebesar 4,06 dari 5 poin skala likert. Sehingga dapat disimpulkan pengguna mandiri online dapat dikategorikan loyal terhadap sistem tersebut. Maka dapat disimpulkan hasil analisis deskriptif dalam penelitian ini juga menunjukan hal serupa, bahwa e-loyalty pengguna mandiri online dipengaruhi oleh e-service quality dari sistem tersebut.

Temuan penelitian terkait $e$-service quality berpengaruh terhadap e-loyalty sejalan dengan penelitian Charles K et al., (2016) yang meneliti tentang penggunaan $e$-banking di Nigeria, serta Kim (2010) yang meneliti persepsi e-service quality konsumen AS dan Korea Selatan.

\section{Hubungan Variabel E-Satisfaction Terhadap E-Loyalty.}

Hasil pengujian hipotesis hubungan $e$ satisfaction terhadap e-loyalty memberikan kesimpulan bahwa hubungan tersebut memiliki arah yang positif dan signifikan. Kesimpulan ini terlihat dari nilai jalur koefisien yang bernilai positif yaitu sebesar 0,501 dan t hitung sebesar 5,465 (lebih besar dari t tabel 1,96). Dapat disimpulkan bahwa sikap loyal pengguna sistem mandiri online akan meningkat seiring dengan rasa puas yang dirasakan oleh pengguna sistem mandiri online tersebut.

Dalam penelitian ini diperoleh bahwa nilai rata-rata (mean) dari masing- masing indikator dalam variabel e-satisfaction bernilai 4,14. Hasil pengujian deskriptif untuk variabel $e$ satisfaction pada nasabah Bank Mandiri pengguna mandiri online menunjukkan hasil yang baik, dan dalam penelitian ini setuju bahwa tingkat kepuasan pengguna sistem mandiri online dalam kategori baik. Kemudian di dapatkan nilai rata - rata variabel e-loyalty sebesar 4,06. Nilai rata - rata tersebut mencerminkan bahwa $e$-loyalty pada penelitian ini berkategori baik. Dapat disimpulkan bahwa pengguna mandiri online dapat dikategorikan loyal terhadap sistem tersebut. Maka dapat disimpulkan hasil analisis deskriptif dalam penelitian ini juga menunjukan hal senada, bahwa $e$-satisfaction memiliki hubungan yang positif dan signifikan terhadap e-loyalty pengguna mandiri online.

Hasil uji hipotesis terkait hubungan $e$ satisfaction terhadap e-loyalty sejalan dengan penelitian Mega et al., (2016) dan juga Othman 
et al., (2016). Ketika pelanggan merasa puas, loyalitas meningkat secara otomatis dan pelanggan akan tetap memilih penyedia layanan tersebut untuk jangka waktu yang lebih lama (Othman et al., 2016).

\section{E-Satisfaction, variabel mediasi E-service quality terhadap $E$-loyalty pengguna mandiri online.}

Berdasar tabel 6 (pengaruh tidak langsung), dapat dilihat nilai koefisien jalur tidak langsung bernilai 0,353. Nilai tersebut menunjukan arah yang bernilai positif. Sedangkan t-hitung bernilai 5,072, lebih besar dari t-tabel $(1,96)$ sehingga menunjukan signifikansi. Angka tersebut menunjukkan bahwa terdapat signifikansi dan hubungan positif pada variabel e-service quality terhadap e-loyalty dengan melalui variabel e-satisfaction. Hubungan langsung antara e-service quality sistem mandiri online dengan e-loyalty juga positif dan signifikan. Sehingga e-satisfaction pada penelitian ini berperan sebagai variabel mediasi parsial.

Dapat diartikan bahwa, ketika pengguna mandiri online merasa puas terhadap kualitas pelayanan dari sistem tersebut, maka akan terbentuk sikap loyal pengguna untuk terus menggunakan sistem mandiri online. Maka semakin tinggi kualitas pelayanan yang diberikan dari sistem mandiri online, kepuasan pengguna sistem tersebut pun akan semakin tinggi, dan berimplikasi pada loyalitas mereka terhadap sistem mandiri online yang semakin meningkat pula. Hasil penelitian ini sejalan dengan penelitian Asad ahmad (2017) yang meneliti kualitas layanan e-commerce di India.

\section{Keterbatasan Penelitian}

1. Lokasi dalam penelitian ini hanya mencakup wilayah Bank Mandiri Area Jember yang meliputi enam kota yaitu Jember, Bondowoso, Banyuwangi, Situbondo dan Probolinggo, Lumajang. Belum mencakup wilayah generelisasi yang lebih luas, seperti kota-kota lain di Indonesia.

2. Penelitian ini terfokus pada kualitas layanan online dalam konteks sistem e-banking mandiri online. Hal tersebut menyebabkan tidak dapat digeneralisasinya model dan hasil penelitian pada objek diluar sistem $e$ banking dengan alasan perbedaan penggunaan konstruk dalam e-service quality. Dalam penelitian terdahulu (Sheng \& Liiu, 2010; Kandulaapati \& Belamkonda, 2014; Kiim, 2010; Asad Ahmad et al., 2017; Cemal Zehir et al., 2014) yang terfokus pada kualitas layanan e-commerce, menggunakan indikator fullfilment dalam konstruk $e$ service quality. Fullfilment merupakan tingkat bagaimana sebuah situs website memberikan janji layanan, ketersediaan produk/jasa agar dapat dipenuhi, serta tepat waktu sesuai dengan yang dijanjikan (Parasuraman et al., 2005).

\section{KESIMPULAN DAN SARAN \\ Kesimpulan}

Berdasarkan pembahasan yang telah dipaparkan pada bab sebelumnya, maka pada penelitian penelitian ini, kesimpulan yang dapat diambil adalah sebagai berikut:

1. Kualitas layanan dari sistem mandiri online memiliki pengaruh yang positif dan siginifikan terhadap kepuasan penggunanya Kemudahan akses, fungsi teknis dari sistem, tingkat keamanan, tingkat sejauh mana penanganan terhadap sebuah masalah, ketersediaan call center, serta design sebuah sistem mandiri online, memiliki pengaruh yang signifikan terhadap keberhasilan Bank Mandiri dalam memberikan kepuasan terhadap nasabahnya khususnya pengguna mandiri online.

2. Hasil penelitian menunjukan bahwa variabel E-Service Quality berpengaruh terhadap ELoyalty secara positif dan signifikan pada pengguna mandiri online. Dimensi efficiency yaitu kemudahan akses, system availability yaitu terkait dengan fungsi teknis dari sebuah sistem, privacy yaitu terkait dengan tingkat keamanan sebuah sistem, responsiveness yang terkait dengan penanganan terhadap sebuah masalah pada sistem, contact yaitu terkait dengan ketersediaan customer service yang online, serta web design yaitu terkait dengan tata letak serta tampilan pada sebuah sistem, semua dimensi tersebut berpengaruh signifikan terhadap tingkat loyalitas pengguna mandiri online. Artinya semakin baik kualitas pelayanan dari sistem mandiri online, maka tingkat loyalitas dari pengguna sistem tersebut akan semakin besar.

3. Kepuasan pengguna sistem mandiri online berrpengaruh positif dan signifiikan 
terhadap sikap loyal pengguna tersebut. Keseluruhan indikator e-satisfaction yang diteliti, berpengaruh pada loyalitas pengguna mandiri online yaitu perasaan senang terhadap keseluruhan pengalaman bertransaksi, senang dengan keamanan sistem, serta senang terhadap tampilan sistem mandiri online. ini menunjukkan bahwa semakin baik pengelolaan kepuasan pengguna mandiri online, maka akan semakin besar pula tingkat loyalitas pengguna tersebut.

4. Hasil penelitian menunjukan bahwa $e$ satisfaction bertindak sebagai variabel mediasii antara $e$-service quality terhadap $e$ loyalty. Hasil tersebut menunjukkan bahwa tinggi rendahnya perasaan puas dan sikap loyal pengguna sistem mandiri online dipengaruhi oleh kualitas layanan dari sistem mandiri online tersebut.

\section{Saran}

Saran pada penelitian ini adalah:

1. Hasil penelitian ini dapat memberikan manfaat secara praktis serta informasi bagi Bank Mandiri mengenai kualitas layanan sistem mandiri online dan kaitannya dengan kepuasan serta loyalitas penggunanya. Dengan peningkatan layanan terhadap sistem mandiri online melalui dimensi efficiency, system availability, privacy, responsiveness, contact dan web design diharapkan dapat meningkatkan perasaan senang pengguna terhadap sistem mandiri online sehingga untuk dampak jangka panjang pengguna akan bersikap loyal dengan menjadikan sistem mandiri online sebagai pilihan pertamanya dalam bertransaksi finansial, serta memberikan rekomendasi terkait sistem tersebut kepada orang lain.

2. Penelitian ini dapat menjadi bahan masukan dalam pengelolaan sistem e-banking khususnya mandiri online. Ditengah kemajuan teknologi yang semakin pesat, Bank Mandiri perlu untuk melakukan penilaian secara berkala apakah layanan sistem mandiri online yang diberikan telah berdampak pada perasaan puas dan sikap loyal pada penggunanya. Bank Mandiri juga perlu melakukan edukasi kepada nasabah terkait kecanggihan dan kemudahan transaksi finansial yang ditawarkan melalui penggunaan sistem mandiri online. Sehingga apabila hal tersebut dijalankan, Bank Mandiri memiliki peluang untuk unggul dalam produk e-banking nya, khususnya mandiri online.

\section{DAFTAR PUSTAKA}

Ahmad, A., Rahman, O., \& naved khan, M. (2017). Exploring the role of website quality and hedonism in the formation of esatisfaction and e-loyalty: evidence from internet users in India. Journal of Research in Interactive Marketing, 11(3), 246-267.

Al-Hawari, M. A. A. (2014). Does customer sociability matter? Differences in equality, e-satisfaction, and e-loyalty between introvert and extravert online banking users. Journal of Services Marketing, 28(7), 538-546. https://doi.org/10.1108/JSM-02-20130036

Anderson, Rolph and Srini S. Srinivasan. 2003. "E-satisfaction and e-loyalty a contigency framework, psychology \& marketing". Journal of Psychology and Marketing, Vol. 20 (2): 123-138.

Anderson, R., \& Srinivasan, srini s. (2003). Esatisfaction and e-loyalty a contigency framework, psychology \& marketing. Journal of Psychology and Marketing, 20(2), 123-138.

Anggraeni, N. M. S., \& Yasa, N. N. K. (2012). E-Service Quality Terhadap Kepuasan Dan Loyalitas Pelanggan Dalam Penggunaan Internet Banking. Jurnal Keuangan Dan Perbankan, 16(2), 293 $306 . \quad$ Retrieved from http://jurkubank.wordpress.com

Griffin. (2005). Customer Loyalty. Jakarta: Penerbit Erlangga.

Kandulapati, S., \& Shekhar Bellamkonda, R. (2014). E-service quality: a study of online shoppers in India. American Journal of Business, 29(2), 178-188. https://doi.org/10.1108/ajb-05-2013-0030

$\mathrm{K}$, C., oni oyerinde $\mathrm{j}$, ayo aderonke atinuke, ibukun o, A., \& Eweoya. (2016). Ebanking users behaviour: e-service quality, 
attitude, and customer satisfaction. International Journal of Bank Marketing, 34(3). Retrieved from http://dx.doi.org/10.1108/IJBM-12-2014$\underline{0175}$

Kim, J. H., \& Kim, C. (2010). E-service quality perceptions: A cross-cultural comparison of american and Korean consumers. Journal of Research in Interactive Marketing, 4(3), 257-275. https://doi.org/10.1108/175059310110706 $\underline{04}$

Parasuraman, A., Zeithaml, V. A., \& Malhotra, A. (2005). E-S-QUAL a multiple-item scale for assessing electronic service quality. Journal of Service Research, 7(3), 213233.https://doi.org/10.1177/109467050427 1156.

Putra, D. (2017). OJK: Empat Tahun Pengguna E-Banking Meningkat 270\%. Retrieved from http://infobanknews.com/empat-tahunpengguna-e-banking-meningkat-270.

Othman, A., Chowdhury, I., Bo, Y., Omar, A., \& Osman, L. (2015). Key Drivers of Customer Loyalty in Online Banking. Annals of Management Science, 4(1), 89110.

https://doi.org/10.24048/ams4.no1.201589

Prisanti, M. Della, Suyadi, I., \& Arifin, Z. (2017). Pengaruh E-Service Quality dan ETrus terhadap E-Customer Satisfaction serta Implikasinya terhadap E-Customer Loyalty. Journal of Business Studies, 2(1), 20.

Singarimbun, M., \& Sofian, E. (2009). Metode Penelitian Survai. Jakarta: LP3ES..

Sheng, T., \& Liu, C. (2010). An empirical study on the effect of e-service quality on online customer satisfaction and loyalty. Nankai Business Review International, 1(3),273283.

https://doi.org/10.1108/204087410110692 05
Zehir, C., Sehitoglu, Y., Narcikara, E., \& Zehir, S. (2014). E-S-Quality, Perceived Value and Loyalty Intentions Relationships in Internet Retailers. Procedia - Social and Behavioral Sciences, 150, 1071-1079. https://doi.org/10.1016/j.sbspro.2014.09.12 0 